Article

\title{
Exploring the Potential of Nitric Oxide and Hydrogen Sulfide (NOSH)-Releasing Synthetic Compounds as Novel Priming Agents against Drought Stress in Medicago sativa Plants
}

\author{
Chrystalla Antoniou ${ }^{1}$, Rafaella Xenofontos ${ }^{1}$, Giannis Chatzimichail ${ }^{1}$, Anastasis Christou ${ }^{2}$, \\ Khosrow Kashfi ${ }^{3,4}$ (D) and Vasileios Fotopoulos ${ }^{1, *(D)}$ \\ 1 Department of Agricultural Sciences, Biotechnology and Food Science, Cyprus University of Technology, \\ 3603 Lemesos, Cyprus; chrystalla.antoniou@cut.ac.cy (C.A.); rafaellaxen@gmail.com (R.X.); \\ y.hadjimichael@theo.ac.cy (G.C.) \\ 2 Agricultural Research Institute, Ministry of Agriculture, Rural Development and Natural Recourses, \\ P.O. Box 22016, 1516 Nicosia, Cyprus; anastasis.christou@arinet.ari.gov.cy \\ 3 Department of Molecular, Cellular and Biomedical Sciences, Sophie Davis School of Biomedical Education, \\ City University of New York School of Medicine, New York, NY 10031, USA; kashfi@med.cuny.edu \\ 4 Graduate Program in Biology, City University of New York Graduate Center, New York, NY 10016, USA \\ * Correspondence: vassilis.fotopoulos@cut.ac.cy; Tel.: +357-25-002418; Fax: +357-25-002632
}

Received: 10 December 2019; Accepted: 2 January 2020; Published: 10 January 2020

\begin{abstract}
Land plants are continuously exposed to multiple abiotic stress factors like drought, heat, and salinity. Nitric oxide $(\mathrm{NO})$ and hydrogen sulfide $\left(\mathrm{H}_{2} \mathrm{~S}\right)$ are two well-examined signaling molecules that act as priming agents, regulating the response of plants to stressful conditions. Several chemical donors exist that provide plants with $\mathrm{NO}$ and $\mathrm{H}_{2} \mathrm{~S}$ separately. $\mathrm{NOSH}$ is a remarkable novel donor as it can donate $\mathrm{NO}$ and $\mathrm{H}_{2} \mathrm{~S}$ simultaneously to plants, while NOSH-aspirin additionally provides the pharmaceutical molecule acetylsalicylic acid. The current study aimed to investigate the potential synergistic effect of these molecules in drought-stressed Medicago sativa L. plants by following a pharmacological approach. Plants were initially pre-treated with both donors (NOSH and NOSH-aspirin) via foliar spraying, and were then subsequently exposed to a moderate water deficit while $\mathrm{NO}$ and $\mathrm{H}_{2} \mathrm{~S}$ inhibitors (cPTIO and $\mathrm{HA}$, respectively) were also employed. Phenotypic and physiological data showed that pre-treatment with NOSH synthetic compounds induced acclimation to subsequent drought stress and improved the recovery following rewatering. This was accompanied by modified reactive-oxygen and nitrogen-species signaling and metabolism, as well as attenuation of cellular damage, as evidenced by altered lipid peroxidation and proline accumulation levels. Furthermore, real-time RT-qPCR analysis revealed the differential regulation of multiple defense-related transcripts, including antioxidant enzymes. Overall, the present study proposed a novel role for NOSH compounds as efficient plant priming agents against environmental constraints through the coordinated regulation of multiple defense components, thus opening new horizons in the field of chemical priming research toward the use of target-selected compounds for stress tolerance enhancement.
\end{abstract}

Keywords: alfalfa; hydrogen sulfide; aspirin; antioxidants; proline; nitric oxide; drought; priming

\section{Introduction}

Abiotic stress factors represent major elements limiting global agricultural productivity [1]. The increased frequency of extreme environmental events resulting from undisputed climatic 
change significantly influences plant growth and development. Close examination of plant-to-plant communication in field conditions has revealed the development of unique strategies from plants as a response to abiotic stress factors, with one of the most intriguing being through priming for enhanced defence responses. The process of priming involves prior exposure to an abiotic or biotic stressor, thus rendering a plant more tolerant to future exposure [2]. An analogy therefore exists with the concept of vaccination in animals, where the administration of antigenic material results in the stimulation of adaptive immunity to a disease, and ultimately, the prevention or amelioration of the effects of pathogen infection. Although the process of priming has been known for decades, it has only recently been suggested that it can improve crop tolerance to environmental stressors in the field [3]. Priming can also be accomplished by applying natural or synthetic chemical compounds that act as signal transducers, thus "switching on" plant defence systems.

The use of chemical compounds as priming agents has indeed been shown to significantly enhance plant tolerance in various crop and non-crop species against a range of different individually applied abiotic stresses, with this field of study attracting increasing attention. Several types of molecules have the potential to act as a priming agent under specific conditions against a range of different environmental stressors [2]. A survey of relevant literature reveals a broad range, including amino acids (e.g., proline [4]), hormones (e.g., salicylic acid [5]), reactive oxygen-nitrogen-sulfur species (RONSS [6,7]), melatonin [8], and even water (i.e., hydropriming [9]). Reactive oxygen (e.g., $\mathrm{H}_{2} \mathrm{O}_{2}$ ), nitrogen (e.g., $\mathrm{NO}$ ), and sulfur (e.g., $\mathrm{H}_{2} \mathrm{~S}$ ) species are of particular interest as they represent the key molecules involved in cellular signaling processes and gene regulation during stress and play a crucial role in the stress acclimation of plants $[10,11]$. Several reports have now led to the identification of a complex interaction between reactive oxygen species (ROS) and reactive nitrogen species (RNS), in which both reactive species are utilized by plants as signal transduction molecules during fundamental cellular and biological processes [10]; interestingly, recent reports have suggested that reactive sulfur species (RSS) may actually be additional players in this interaction [12].

NOSH-aspirin (NOSH-A; NBS-1120) is a novel hybrid synthetic compound belonging to the NSAID group that was first established as a high-potency compound for its anti-inflammatory action, e.g., anti-cancer [13-15] and neuroprotective activity in mammals [16]. NOSH-A is a donor that simultaneously releases nitric oxide $(\mathrm{NO})$, hydrogen sulfide $\left(\mathrm{H}_{2} \mathrm{~S}\right)$, and aspirin (acetylsalicylic acid), while $\mathrm{NOSH}$ donates $\mathrm{NO}$ and $\mathrm{H}_{2} \mathrm{~S}$. NOSH compounds represent very promising priming agent candidates due to this simultaneous donation, while they also avoid odor problems commonly associated with standard $\mathrm{H}_{2} \mathrm{~S}$ donors, such as NaHS (smell of rotten eggs), thanks to its patented formulation. $\mathrm{NO}$ and $\mathrm{H}_{2} \mathrm{~S}$ are two gasotransmitters with important physiological roles in plants, including their involvement in stress tolerance mechanisms [17]. Salicylates (e.g., salicylic acid) are produced by plants as part of their defense systems against biotic and abiotic stress conditions. Plant treatments with any of the three compounds strongly improved the germination and later plant growth in drought and salt stress conditions $[17,18]$. The aim of the present study was to examine the potential priming effects of NOSH and NOSH-aspirin pre-treatment in Medicago sativa plants growing under prolonged exposure to drought. A combinatorial physiological, biochemical, and molecular approach was employed toward this objective, while inhibitors of $\mathrm{NO}$ and $\mathrm{H}_{2} \mathrm{~S}$ biosynthesis were also used, in order to decipher whether they present a cumulative protective role or act antagonistically.

\section{Materials and Methods}

\subsection{Plant Material and Experimental Treatments}

Alfalfa (Medicago sativa L.) seeds were generously obtained by the Cyprus National Genebank and Herbarium and sown after scarification in 7-cm diameter plastic pots (10 seeds per pot) filled with a mixture of sterile potting soil:perlite (3:1). Seeds were stratified in the dark for 4 days at $4{ }^{\circ} \mathrm{C}$ and subsequently transferred in a growth chamber at $22 / 16^{\circ} \mathrm{C}$ day/night temperatures, at $60-70 \% \mathrm{RH}$, with a photosynthetic photon flux density of $100 \mu \mathrm{mol} \mathrm{m} \mathrm{m}^{-1}$ and a $16 / 8-\mathrm{h}$ photoperiod. Germinated 
seedlings were then thinned to three per pot. Growing plants were watered twice per week for the next 42 days until experimental treatments were applied. Plants were fertilized with commercial nutrient solution (Plant-Prod 20-20-20 Fertilizer, Lambrou Agro, Lemesos, Cyprus) every two weeks. In order to examine the effects of exogenous NOSH and NOSH-A application in plant tolerance to drought, plants were treated once via leaf spraying with $100 \mu \mathrm{M}$ NOSH or NOSH-A (synthesized as previously described [13], and were a gift from Avicenna Pharmaceuticals Inc., New York, NY, USA) diluted in 30\% (v/v) methanol till drip-off. Control samples were also sprayed with the same solvent. Drought stress conditions were achieved by withholding watering for 6 days, resulting in pronounced phenotypic foliar damage (in the form of chlorosis and leaf wilting). Samples were then rewatered to observe the recovery potential after 1 day (day 7). The optimal concentration, solvent, and method of application of NOSH and NOSH-A were chosen following preliminary experimental results where the hybrid donors were applied in gradient concentrations (data not shown). Overall, alfalfa plants were subjected to eleven treatments presented in detail in Table 1. Both inhibitors (cPTIO: NO inhibitor, HA: $\mathrm{H}_{2} \mathrm{~S}$ inhibitor; Sigma-Aldrich, St. Louis, MO, USA) were applied at $100 \mu \mathrm{M}$ based on the existing literature, either solo (for phenotypic observations shown in Supplementary Figure S1) or in mixture with NOSH synthetic compounds (for all measurements presented herein). Leaf samples were harvested both at day 6 (drought stress) as well as at day 7 (1 day after re-watering) to examine the recovery, flash-frozen in liquid nitrogen, and stored at $-80{ }^{\circ} \mathrm{C}$ for subsequent analyses. Experiments were carried out in triplicate using pooled material (each replicate consisted of tissue harvested from a minimum of three independent plants).

Table 1. Treatments carried out in the current experimental setup.

\begin{tabular}{cc}
\hline Treatment Abbreviation & Treatment \\
\hline W-m & Control (methanol) \\
D-m & Drought (methanol) \\
D-N & Drought + NOSH \\
D-NC & Drought + NOSH + cPTIO \\
D-NH & Drought + NOSH + HA \\
D-NCH & Drought + NOSH + cPTIO + HA \\
D-NA & Drought + NOSH-A \\
D-NAC & Drought + NOSH-A + cPTIO \\
D-NAH & Drought + NOSH-A + HA \\
D-NACH & Drought + NOSH-A + cPTIO + HA \\
\hline
\end{tabular}

\subsection{Physiological and Biochemical Measurements}

Stomatal conductance was measured in fully expanded leaves using a $\Delta \mathrm{T}$-Porometer AP4 (Delta-T Devices, Cambridge, UK) following the manufacturer's instructions. Leaf chlorophyll fluorescence representing the photosystem II (PSII) maximum photochemical efficiency (Fv/Fm) was measured with an OptiSci OS-30p Chlorophyll Fluorometer (Opti-Sciences, Hudson, NH, USA). Leaves were dark-adapted for 30 min before fluorescence measurements were carried out. Lipid peroxidation levels, as a widely used cellular damage indicator, were determined from the quantification of malondialdehyde (MDA) content resulting from the thiobarbituric acid reaction, as previously described [19].

\subsection{Reactive Species and Proline Quantification}

Leaf hydrogen peroxide $\left(\mathrm{H}_{2} \mathrm{O}_{2}\right)$ content was determined spectrophotometrically using potassium iodide (KI) as previously described [20]. Nitrite-derived nitric oxide (NO) content was quantified using the Griess reagent as previously described [21]. $\mathrm{H}_{2} \mathrm{~S}$ content was determined following the methodology described by Nashef et al. [22]. Free proline content was measured with the ninhydrin reaction as described by Bates et al. [23]. Proline content was determined from a proline standard curve. 


\subsection{Antioxidant Enzyme Activities}

Soluble proteins were extracted by homogenizing leaf samples $(100 \mathrm{mg})$ in an ice-cold extraction buffer (0.1 M phosphate buffer pH 7.5, 0.5 mM EDTA, 1 mM PMSF). Each homogenate was centrifuged at $16,000 \times g$ at $4{ }^{\circ} \mathrm{C}$ for $20 \mathrm{~min}$, and the supernatant was used for enzymatic activity and protein content assays. Protein content was determined according to the method of Bradford [24] using bovine serum albumin as a standard. Total superoxide dismutase (SOD) activity was assessed by measuring its ability to inhibit the photochemical reduction of nitro blue tetrazolium chloride (NBT), as proposed by Giannopolitis and Ries [25]. Catalase (CAT) activity was assayed by monitoring the $\mathrm{H}_{2} \mathrm{O}_{2}$ reduction by following the methodology of Aebi [26]. A detailed description of the methodology followed for the assay of both SOD and CAT enzymatic activity can be found in Filippou et al. [27]. All enzymatic activity assay results were expressed as specific activity units per milligram of protein.

\subsection{RT-qPCR Analysis}

Total RNA was extracted from leaves using TRIzol (TRI reagent; Sigma-Aldrich, St. Louis, MO, USA), followed by DNase digestion (RNase-free DNase Set; Qiagen, Hilden, Germany). The quality and quantity of RNA was analyzed spectrophotometrically using a Nanodrop 1000 Spectrophotometer (Thermo Scientific, Wilmington, DE, USA), while RNA integrity was checked using gel electrophoresis. For real-time RT-qPCR analyses, $1 \mu \mathrm{g}$ of total RNA was converted into cDNA using a Primescript 1 st Strand Synthesis Kit according to the manufacturer's protocol (Takara, Shiga, Japan). Subsequently, real-time PCR was performed with a Biorad IQ5 (Biorad, Hercules, CA, USA). The reaction mix contained $4 \mu \mathrm{L}$ cDNA in an RT buffer (diluted 1:5), $0.75 \mu \mathrm{M}$ of each primer (see Table S1), and $1 \times$ master mix (SYBRGreen Super Mix, Invitrogen, San Diego, CA, USA). Reactions were carried out using three independent replicates. The thermocycler conditions were: initial denaturation at $95^{\circ} \mathrm{C}$ for $5 \mathrm{~min}$, followed by 40 cycles of amplification $\left(95^{\circ} \mathrm{C}\right.$ for $30 \mathrm{~s}$, annealing temperature (Ta; see Table S1) for 30 $\mathrm{s}$, and $72{ }^{\circ} \mathrm{C}$ for $30 \mathrm{~s}$ ), and a final elongation stage at $72{ }^{\circ} \mathrm{C}$ for $5 \mathrm{~min}$. The relative quantification of transcript levels and the statistical analysis of RT-qPCR data (pairwise fixed reallocation randomization test) were performed using REST software in accordance with Pfaffl et al. [28]. Actin11 was used as a housekeeping reference gene [29].

\subsection{Statistical Analysis}

Statistical analyses were carried out using SPSS v.11 (SPSS Inc., Chicago, IL, USA). Physiological and biochemical measurements were subjected to ANOVA, and then significant differences were determined between individual means using Duncan's post-hoc pairwise comparison test at the $5 \%$ confidence level.

\section{Results}

\subsection{Phenotypic Responses of Alfalfa Plants Pre-Treated with NOSH Synthetic Compounds Prior to Drought} Stress Imposition

The macroscopic (phenotypic) observation of plants showed that NOSH and NOSH-A pre-treated plants that were subsequently drought-stressed had significantly improved vitality, turgor, and greening in comparison with drought-stressed plants. The latter demonstrated extensive chlorosis and loss of turgor that was indicative of stress-related damage at 6 days after stress imposition (Figure 1A).

Rewatering for 1 day revealed that NOSH and NOSH-A pre-treated samples had a notably improved recovery capacity compared with drought-stressed-alone samples; pre-treated plants retained turgor and greening, while stressed-alone plants showed extensive chlorosis and initial signs of necrosis (Figure 1B). Interestingly, plants were left to grow following rewatering for another 6 days without any further watering to replicate a second "wave" of drought stress. Phenotypic observations revealed that NOSH and NOSH-A pre-treated plants maintained their growth and vitality, while drought-stressed-alone plants showed extensive levels of tissue necrosis (data not shown). 




B)


Figure 1. Phenotypic effects of NOSH and NOSH-aspirin $(100 \mu \mathrm{M})$ pre-treatment on alfalfa plants (A) exposed to drought stress for 6 days by withholding watering, as well as (B) following rewatering for 1 day (day 7), with respective controls ( $\mathrm{MeOH}$-treated plants). Representative plants from selected treatments are shown. A full set of treatment phenotypes including inhibitors is shown in Supplementary Figure S1.

3.2. Verification of the Successful Donation of Nitric Oxide and Hydrogen Sulfide Following NOSH and NOSH-A Pre-Treatment of Alfalfa Plants

The donations of nitric oxide and hydrogen sulfide following NOSH and NOSH-A pre-treatment in alfalfa plants was evaluated by quantifying the nitrite-derived $\mathrm{NO}$ content and $\mathrm{H}_{2} \mathrm{~S}$ content after one day of hybrid donor application. Plants treated with either priming agent displayed significantly higher $\mathrm{NO}$ and $\mathrm{H}_{2} \mathrm{~S}$ levels compared with the respective untreated samples, while use of appropriate 
inhibitors (cPTIO for $\mathrm{NO}, \mathrm{HA}$ for $\mathrm{H}_{2} \mathrm{~S}$ ) resulted in a significant lowering of the reactive species content (Figure 2) indicative of successful compound donation.

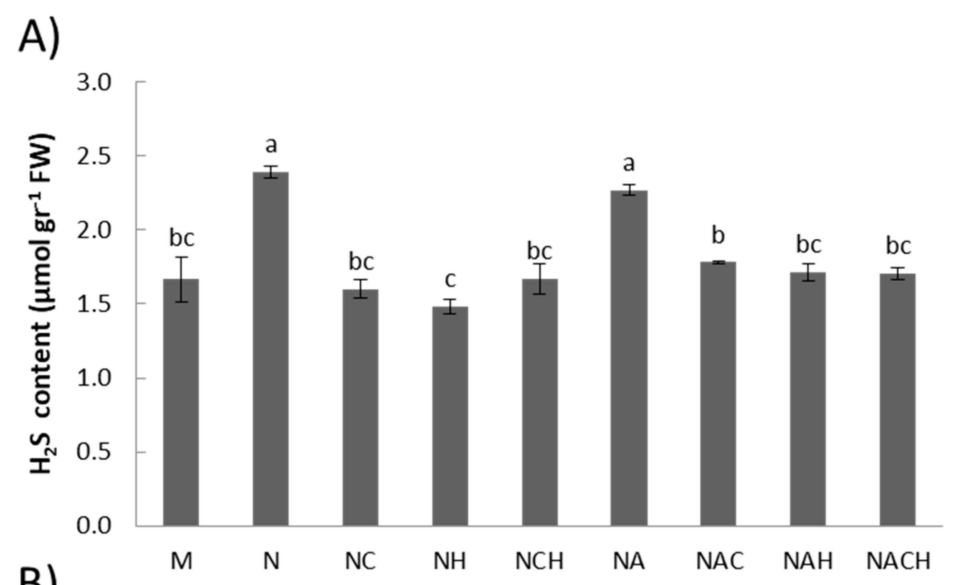

B)

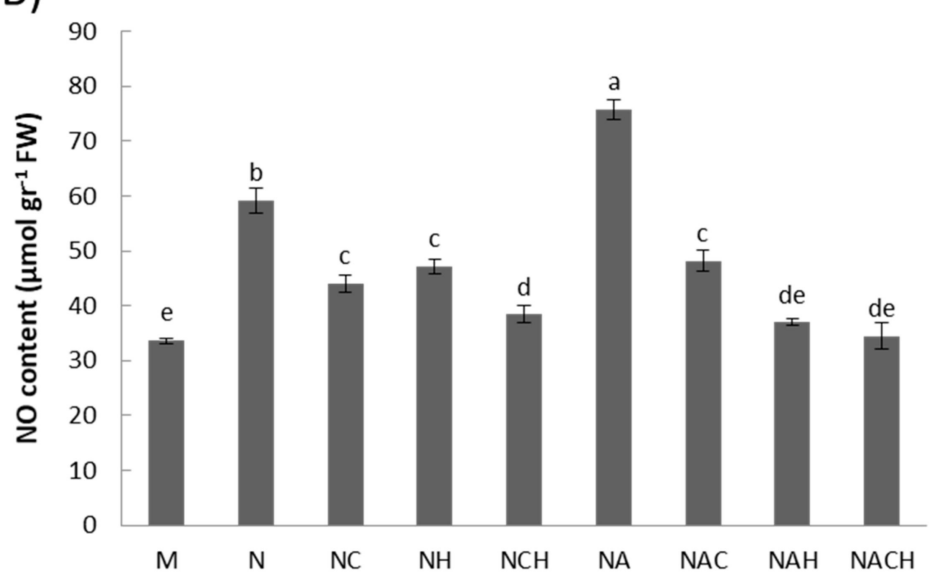

Figure 2. Quantification of (A) nitrite-derived $\mathrm{NO}$ content and (B) $\mathrm{H}_{2} \mathrm{~S}$ content 1 day after application with NOSH synthetic compounds $(100 \mu \mathrm{M})$ in alfalfa plants. Data are the means \pm SE of three replications. Bars with different letters are significantly different $(p<0.05)$. Treatment abbreviations are explained in Table 1. FW: Fresh Weight.

\subsection{Physiological and Cellular Damage Responses of NOSH and NOSH-A Pre-Treated Plants under} Drought Stress

Measurements of the physiological parameters indicated that drought-stressed plants had significantly lower stomatal conductance and chlorophyll fluorescence levels compared with watered plants, which was indicative of a stressed state. Contrarily, NOSH and NOSH-A pre-treated and subsequently stressed plants had significantly ameliorated stomatal conductance and chlorophyll fluorescence levels compared with drought-stressed samples (Figure 3A,C). Similar trends were also observed in the ability of plants to recover following rewatering (Figure 3B,D). The application of both inhibitors in NOSH-treated plants under drought stress conditions resulted in physiological parameters similar to ones recorded in unprimed, drought-stressed plants. Interestingly, the joint application of inhibitors in NOSH-A-treated plants did not reverse the protective effect, suggesting a key role of acetylsalicylic acid in the amelioration of drought-induced physiological damage. 
A)

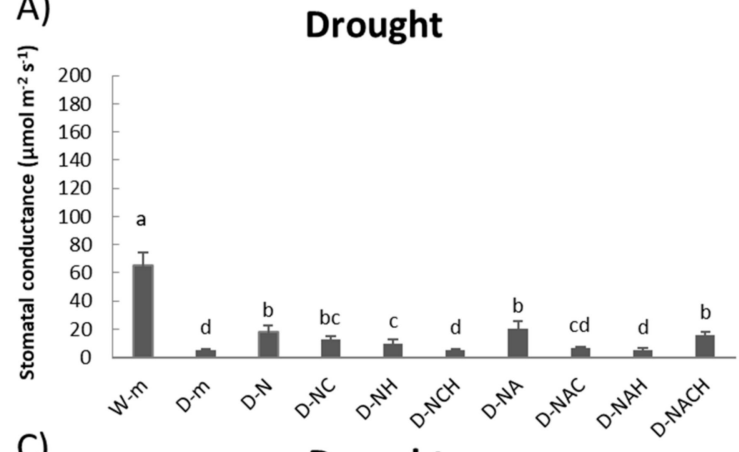

C)

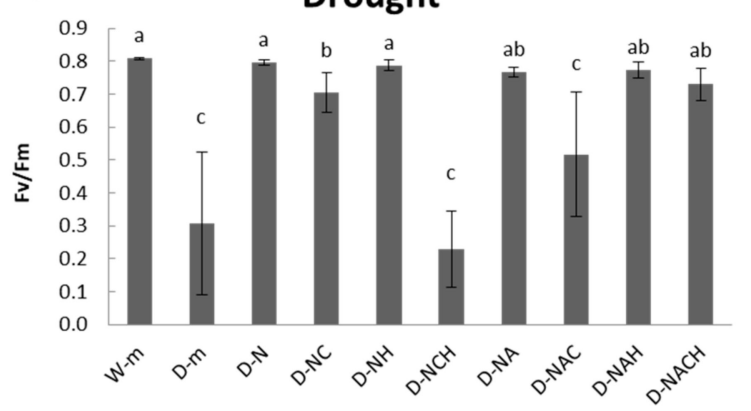

B)
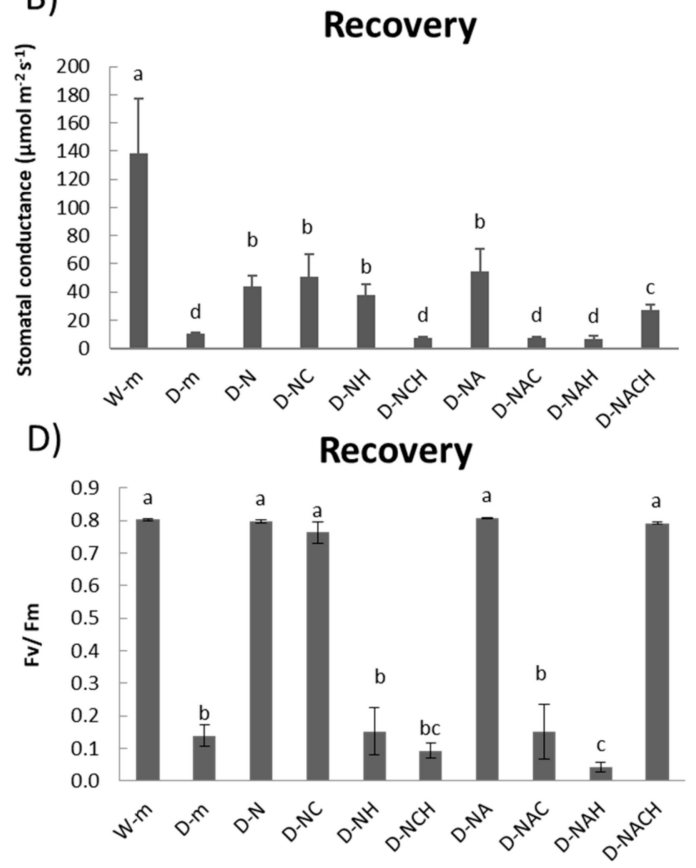

Figure 3. Effect of NOSH and NOSH-aspirin $(100 \mu \mathrm{M})$ pre-treatment on the stomatal conductance $(\mathbf{A}, \mathbf{B})$ and chlorophyll fluorescence (C,D) of leaves of alfalfa plants exposed for 6 days either to drought stress by withholding watering $(\mathbf{A}, \mathbf{C})$, as well as following rewatering for 1 day ((B,D); day 7$)$. Data are means \pm SE of three replications. Bars with different letters are significantly different $(p<0.05)$. Treatment abbreviations are explained in Table 1.

An examination of cellular damage levels was performed by means of the spectrophotometric determination of lipid peroxidation. Significant membrane damage was observed under drought conditions; however, the MDA content was lowered following NOSH and NOSH-aspirin pre-treatment, with both $\mathrm{NOSH}$ and $\mathrm{NOSH}$-aspirin providing statistically significant protection in comparison with drought-stressed samples (Figure 4A). Interestingly, most treatments linked with NOSH and NOSH-A priming managed to recover significantly following rewatering in terms of lipid peroxidation levels, with the exception of plants treated with NOSH and both inhibitors, as well as plants treated with NOSH-A and HA (Figure 4B).

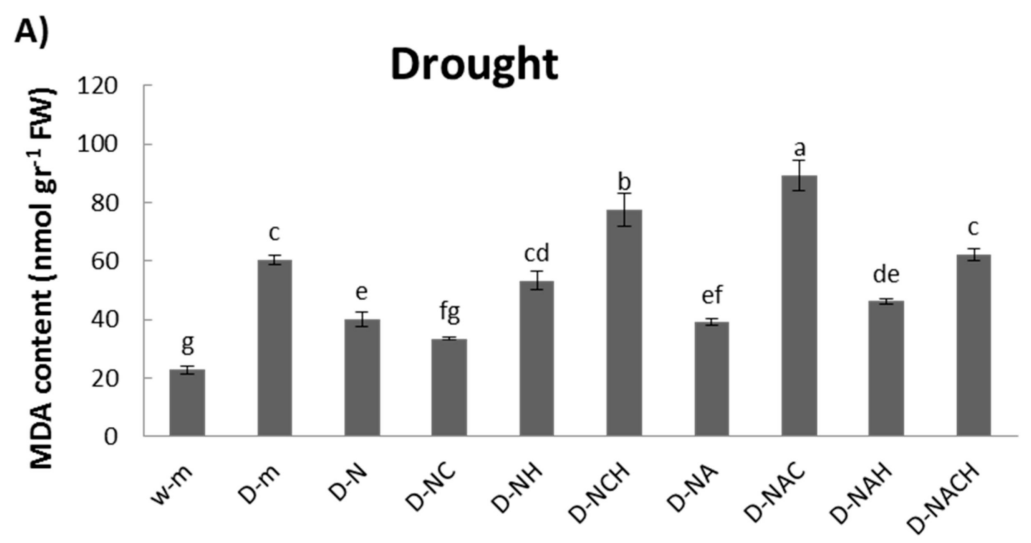

Figure 4. Cont. 


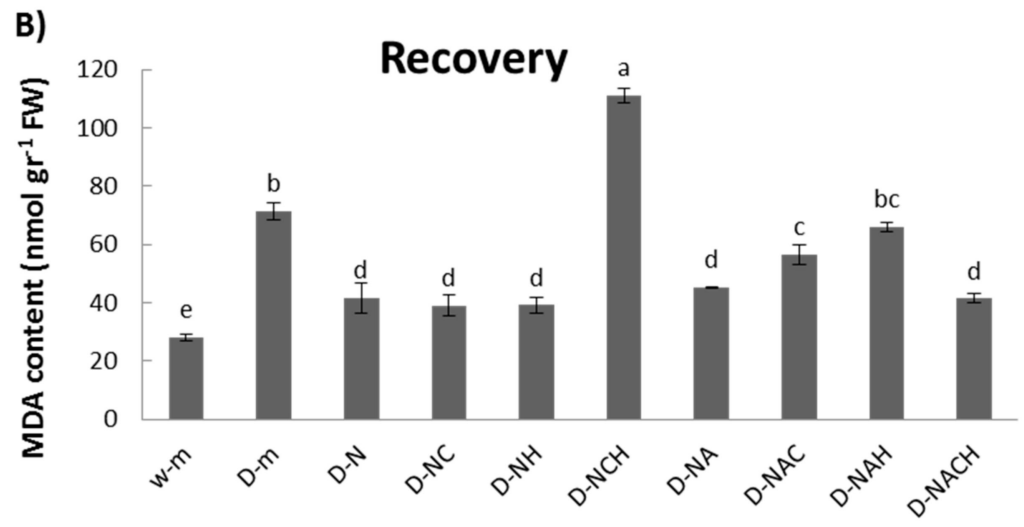

Figure 4. Effect of NOSH and NOSH-aspirin $(100 \mu \mathrm{M})$ pre-treatment on the level of lipid peroxidation, measured as malondialdehyde (MDA) content, in the leaves of alfalfa plants (A) exposed for 6 days to drought stress by withholding watering, as well as (B) following rewatering for 1 day (day 7). Data are means \pm SE of three replications. Bars with different letters are significantly different $(p<0.05)$. The treatment abbreviations are explained in Table 1. FW: Fresh Weight.

3.4. Regulation of Nitro-Oxidative Homeostasis in Alfalfa Plants under Drought Stress Following NOSH and NOSH-A Pre-Treatment

Abiotic stress conditions are associated with increased levels of reactive oxygen (ROS) and reactive nitrogen (RNS) species content, which are toxic for the cells. During such conditions, the production of ROS and RNS exceeds the capacity of the antioxidative defense systems to remove them, causing nitro-oxidative stress. The quantification of $\mathrm{H}_{2} \mathrm{O}_{2}$ (major ROS) and nitric oxide (NO; major RNS) content revealed a massive induction in drought-stressed plants, which was significantly reversed in $\mathrm{NOSH}$ and NOSH-aspirin pre-treated plants compared with drought-stressed samples (Figure 5A,C). Similar patterns were recorded following rewatering of the plants (recovery phase; Figure 5B,D).
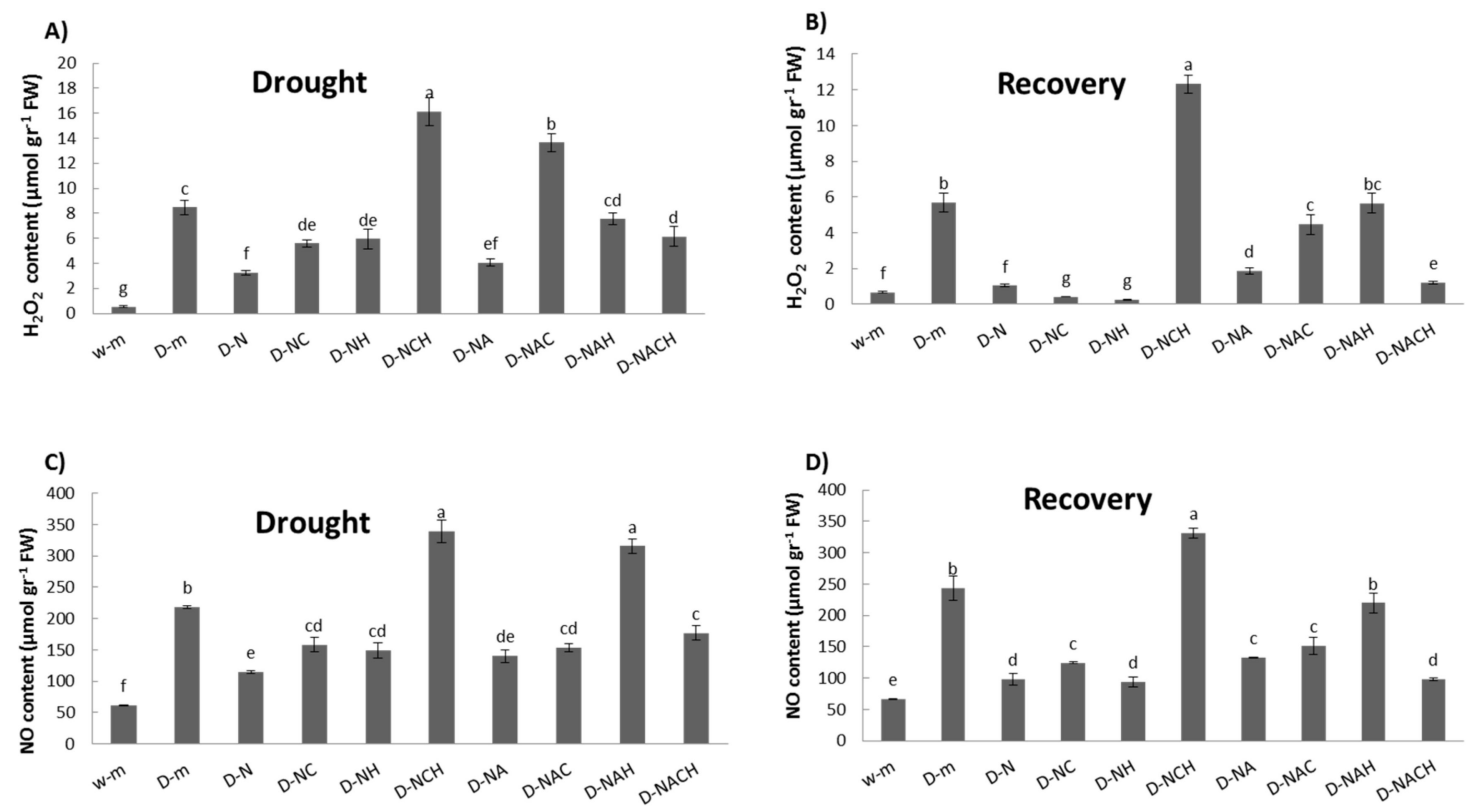

Figure 5. Effect of NOSH and NOSH-aspirin $(100 \mu \mathrm{M})$ pre-treatment on $(\mathbf{A}, \mathbf{B})$ hydrogen peroxide, and (C,D) nitrite-derived NO content in leaves of alfalfa plants $(A, C)$ exposed for 6 days to drought stress by withholding watering, as well as (B,D) following rewatering for 1 day (day 7). Data are means \pm SE of three replications. Bars with different letters are significantly different $(p<0.05)$. Treatment abbreviations are explained in Table 1. FW: Fresh Weight. 
The enzymatic activity of two key antioxidants (SOD and CAT) were evaluated. SOD dismutates superoxide radicals to hydrogen peroxide, while CAT directly scavenges hydrogen peroxide. Both enzymes appeared to be regulated in response to stress and priming agent pre-treatment in a differential manner (Figure 6A,C). Few specific enzymatic activity signatures were identified, with the main points being the significant induction in SOD and CAT activity in plants under drought stress compared with control ones, and the significant suppression of SOD and CAT activity following NOSH pre-treatment compared with unprimed, drought-stressed samples. The antioxidant activity profile under recovery (following rewatering) followed a reverse pattern, whereby NOSH and NOSH-A pre-treated plants had higher SOD and CAT activity levels compared with unprimed, drought-stressed plants (Figure 6B,D).


D)

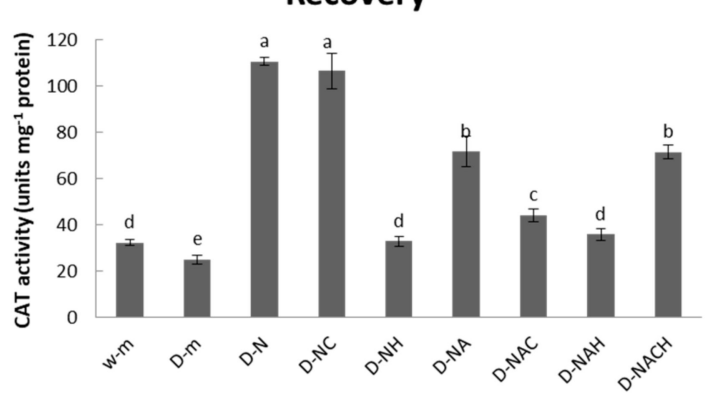

Figure 6. Effect of NOSH and NOSH-aspirin $(100 \mu \mathrm{M})$ pre-treatment on superoxide dismutase (SOD; (A)) and catalase (CAT; (C)) enzymatic activity in leaves of drought-stressed Medicago sativa plants exposed for 6 days to drought stress by withholding watering, as well as ((B) SOD; (D) CAT activity) following rewatering for 1 day (day 7). Data are means \pm SE of three replications. Bars with different letters are significantly different $(p<0.05)$. Treatment abbreviations are explained in Table 1.

\subsection{Proline Metabolism in Drought-Stressed Alfalfa Plants Following Priming with NOSH Synthetic Compounds}

Drought stress resulted in the significant accumulation of proline in leaf tissues compared with non-stressed control plants. The increase in proline content in plants pre-treated with NOSH and NOSH-A prior to drought stress imposition was significantly less pronounced compared with that of unprimed stressed plants (Figure 7A). Similar patterns were observed in general in plants under recovery following rewatering for 1 day, with the highest proline levels being recorded in unprimed, drought-stressed plants and NOSH pre-treated plants that were sprayed with both inhibitors and subsequently stressed (Figure 7B). 


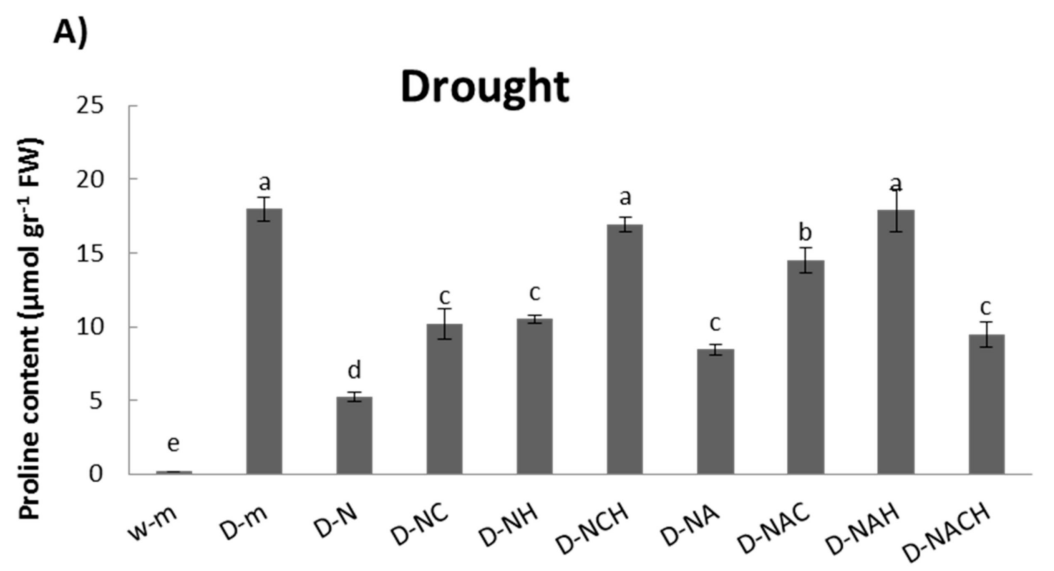

B)

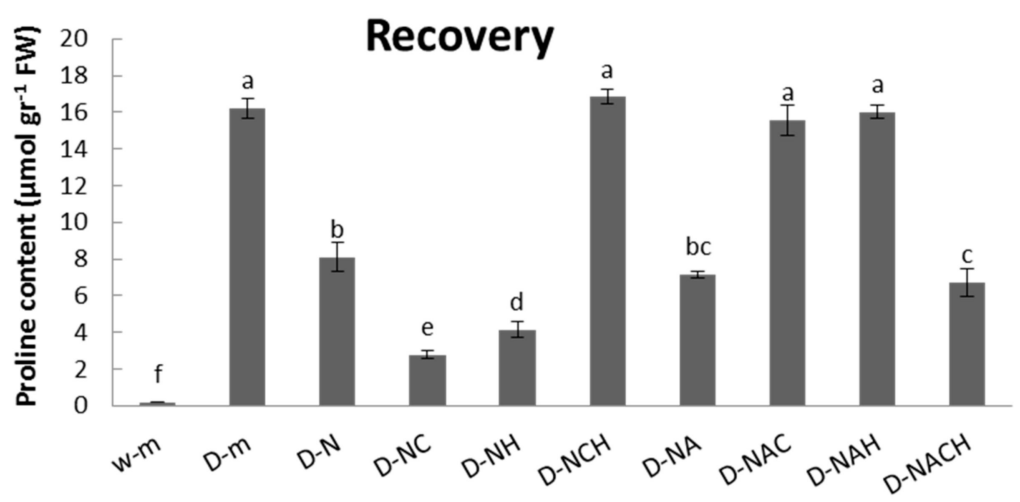

Figure 7. Effect of NOSH and NOSH-aspirin $(100 \mu \mathrm{M})$ pre-treatment on proline content in the leaves of alfalfa plants (A) exposed for 6 days to drought stress by withholding watering, as well as (B) following rewatering for 1 day (day 7). Data are means \pm SE of three replications. Bars with different letters are significantly different $(p<0.05)$. Treatment abbreviations are explained in Table 1.

\subsection{Molecular Characterization of Drought Stress Responses in NOSH and NOSH-A Primed Plants}

Finally, RT-qPCR gene expression analysis was carried out (Figure 8) for key defense-related genes, including major enzymatic antioxidants (GST17, Cu/ZnSOD, FeSOD, cAPX) linked with ROS scavenging, as well as genes involved in NO biosynthesis (NR). In addition, an aquaporin (PIP) was also examined, which is linked with the response to water deficit and transport. Interestingly, NOSH and primarily NOSH-A pre-treated plants under drought stress conditions demonstrated significant transcriptional upregulation for $S O D$ isoforms, which are linked with the dismutation of superoxide radicals to $\mathrm{H}_{2} \mathrm{O}_{2}$ (Figure $8 \mathrm{~A}$ ). In addition, it should be noted that rewatering resulted in the general suppression of most defense-related genes examined in NOSH/NOSH-A pre-treated and subsequently stressed plants compared with both drought-stressed and rewatered plants, as well as primed and stressed plants prior to rewatering (Figure 8B), suggesting that the plants were in a better position to recover without the further transcriptional activation of defense-related genes, which is energy consuming for the plant. 


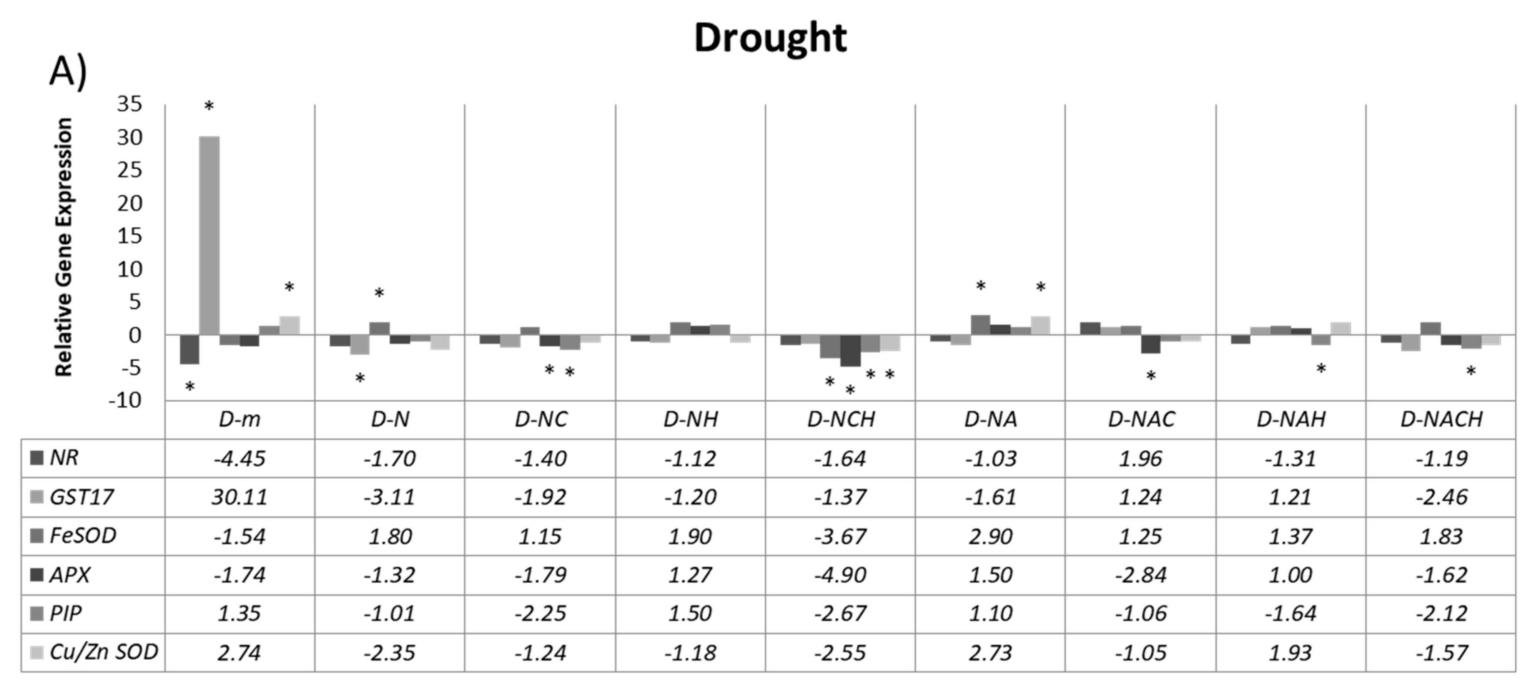

B)

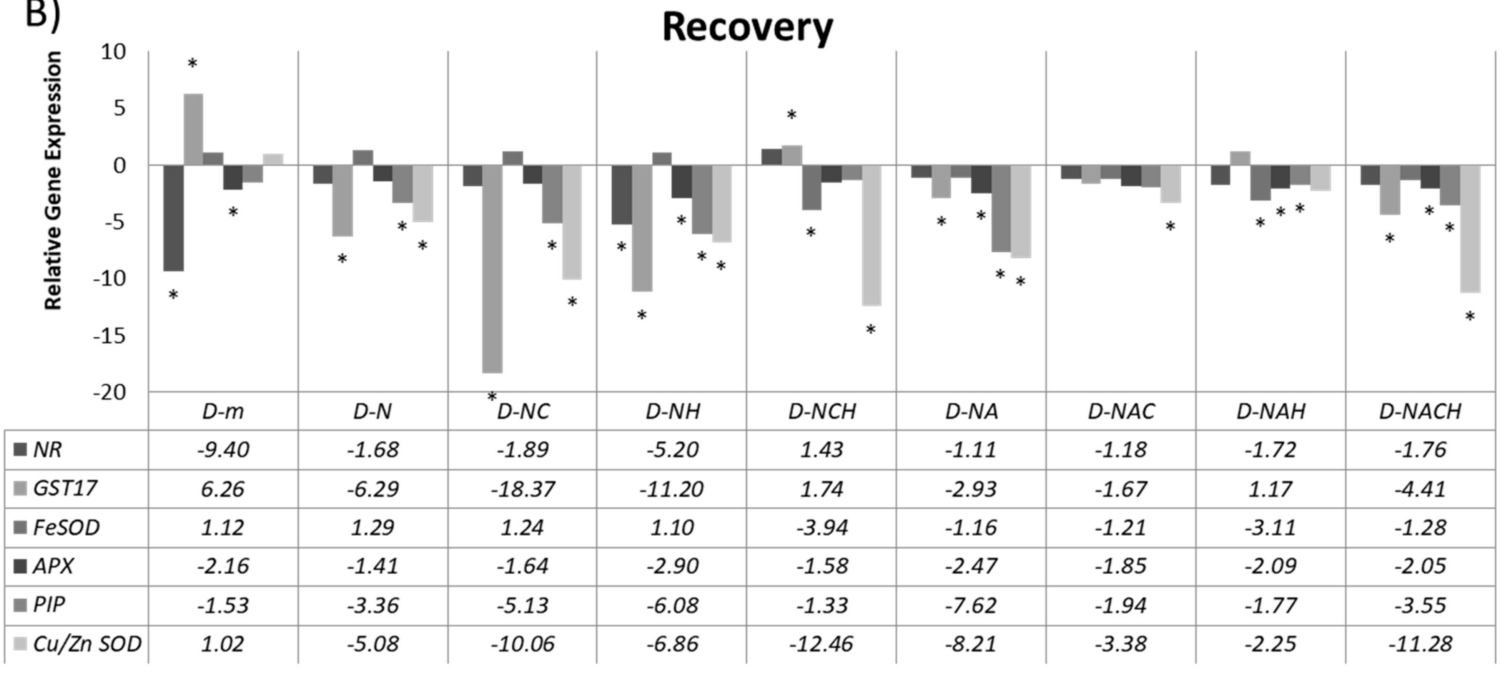

Figure 8. Effect of NOSH and NOSH-aspirin $(100 \mu \mathrm{M})$ pre-treatment on the relative mRNA abundance (fold change relative to unprimed, unstressed samples) of selected transcripts encoding enzymes involved in reactive oxygen species (ROS) metabolism ( $C A P X, C u / Z n S O D, F e S O D)$, detoxification (GST17), nitric oxide biosynthesis (NR), and water transport (PIP) in leaves of alfalfa plants (A) exposed for 6 days to drought stress by withholding watering, as well as (B) following rewatering for 1 day (day 7). Gene expression was assayed using RT-qPCR with three biological repeats. ${ }^{*} p<0.05$, statistically different from control according to a pairwise fixed reallocation randomization test. Treatment abbreviations are explained in Table 1.

\section{Discussion}

Water availability is thought to represent the most important environmental factor shaping plant evolution on earth [30]. Consequently, water deficit is one of the major constraints on agricultural production across ecosystems, thus rendering approaches toward mitigating its detrimental effects of prime importance from both a theoretical and applied point of view [31]. It is well-known that drought stress influences multiple plant metabolic pathways and induces a multitude of cellular responses [32]. Nevertheless, plants have developed an extensive defense apparatus, including valuable components, such as the antioxidant system, the accumulation of osmoprotective compounds, post-translational modifications, etc. [33]. In the present report, novel evidence is provided that highlights the protective effect of hybrid donor NOSH-aspirin against drought stress conditions in alfalfa plants. To our knowledge, this is the first report to show the cross-field application of synthetic 
anti-cancer compounds as plant-priming agents. Notably, these compounds have the added potential benefit of posing a low risk of negative environmental impact as they are donating very low amounts of natural molecules that already exist in plants.

The role of $\mathrm{NO}$ and $\mathrm{H}_{2} \mathrm{~S}$ as key biological players acting as endogenous signaling molecules in plant stress responses is well documented [34]. This is also the case for salicylic acid, which has been long known to be heavily involved in an array of plant responses against abiotic stress factors [35]. Several reports exist that provide supporting information toward the protective effect of each molecule against drought stress when applied individually, in line with current findings. Such a protective function is the result of a coordinated orchestration of improved physiological performance, as well as upregulated antioxidant apparatus and other defense-related pathways.

Stress conditions lead to stomatal closure and limitations in photosynthetic capacity [36]. Similar to $\mathrm{NOSH}$ - and NOSH-A-primed plants under drought stress, the pre-treatment of strawberry plants with NaHS under polyethylene glycol (PEG) stress [19] and with sodium nitroprusside (SNP; NO donor) under $\mathrm{NaCl}$ stress [37] ameliorated chlorophyll fluorescence and stomatal conductance compared with unprimed, stressed samples, potentially leading to an improved maximum photochemical efficiency of photosystem II increased $\mathrm{CO}_{2}$ uptake and improved overall photosynthetic performance. Similarly, salicylic acid (SA) pre-treatment in wheat seedlings under osmotic stress increased their chlorophyll content [38], while SA supplementation to drought-stressed barley plants resulted in an increased net $\mathrm{CO}_{2}$ assimilation rate due to increased stomatal conductance, and eventually in increased plant dry mass [39]. The increased photosynthetic capacity was attributed to chloroplast biogenesis and upregulated photosynthetic enzyme expression following $\mathrm{NaHS}\left(\mathrm{H}_{2} \mathrm{~S}\right.$ donor $)$ application in spinach seedlings [40], while comprehensive proteomic analysis identified the upregulation of a number of proteins belonging to the photosynthetic apparatus following NaHS and SNP pre-treatment in drought-stressed citrus plants, which resulted in the maintenance of photosynthetic functionality and improved recovery of photosystem II under stress conditions [41].

Drought stress is associated with pronounced increases in reactive oxygen and nitrogen species (RONS) levels, which may lead to the significant oxidation of cellular components, so control of RONS and therefore of their metabolism is imperative under stress conditions [42,43]. Drought-induced cellular damage and the resulting loss of membrane integrity was alleviated in NOSH and NOSH-A pre-treated plants, as revealed by the significantly lower MDA content in primed, stressed plants compared with unprimed, drought-stressed plants. Interestingly, amelioration of lipid peroxidation was not as pronounced in plants pre-treated with NOSH-A and both inhibitors, suggesting that acetylsalicylic acid did not provide equal levels of stress protection as a solo application. Furthermore, the observed mitigation of stress-related cellular damage can be attributed at large to the restriction of drought-mediated nitro-oxidative stress, as evidenced by the lower RONS concentration in plants primed with NOSH compounds compared with unprimed ones under drought conditions. Notably, the highest levels of RONS indicative of nitro-oxidative damage were recorded in drought-stressed plants pre-treated with NOSH and both inhibitors, whereas drought-stressed plants pre-treated with NOSH-A and both inhibitors had lower levels of reactive species, suggesting that acetylsalicylic acid induced a certain degree of detoxification. These results are in agreement with those reported by Zhang et al. [44], who also reported that NaHS-pretreated and subsequently stressed plants had lower $\mathrm{H}_{2} \mathrm{O}_{2}$ levels, while Lisjak et al. demonstrated lower NO accumulation in Arabidopsis plants treated with NaHS [45]. Similarly, Christou et al. showed that NaHS [19] and SNP [37] pre-treatment managed to sustain both $\mathrm{H}_{2} \mathrm{O}_{2}$ and $\mathrm{NO}$ content in much lower concentrations in strawberry plants under PEG and salt stress, respectively, in comparison with unprimed, stressed plants.

Increased $\mathrm{H}_{2} \mathrm{O}_{2}$ content in untreated, stressed plants compared with primed and subsequently stressed plants correlates with the higher enzymatic activity of SOD, which dismutates superoxide radicals to $\mathrm{H}_{2} \mathrm{O}_{2}$ [36], in accordance with previous reports [46]. Contrarily, only partial correlation was observed between the total SOD enzymatic activity with corresponding gene expression levels since only one of the two SOD isoenzymes examined herein $(\mathrm{Cu} / \mathrm{ZnSOD})$ was induced in unprimed, 
stressed plants compared with control ones; meanwhile, both isoenzymes ( $\mathrm{Cu} / \mathrm{ZnSOD}, \mathrm{FeSOD})$ were significantly induced in NOSH-A pre-treated plants under stress, whereas no significant difference in the total SOD activity was observed between primed and unprimed plants under stress. The observed induction in FeSOD transcript levels in NOSH and NOSH-A primed plants under drought stress is in agreement with a recent report that demonstrated that treatment with $100 \mu \mathrm{M}$ of NO donor SNP results in a significant induction of FeSOD in mature Medicago truncatula plants [47]. Any observed discrepancies in differences between antioxidant enzyme activities and transcript levels are likely due to organellar specificity or to the involvement of other unknown genetic factors that may regulate the expression of these genes [48], while the lack of correlation between $\mathrm{H}_{2} \mathrm{O}_{2}$ content and CAT activity (which scavenges $\mathrm{H}_{2} \mathrm{O}_{2}$ to oxygen and water [36] in $\mathrm{NOSH}$ and $\mathrm{NOSH}-\mathrm{A}$ primed plants could be due to the complexity of the ROS scavenging system, which involves several other components (e.g., APX), as well as non-enzymatic antioxidants (e.g., ascorbic acid, tocopherols, and glutathione) [36].

It should be noted that a stress-related GST (GST17), known to act as a detoxifying molecule of oxidation products following their conjugation with GSH [49], was shown to be significantly induced following drought stress imposition, whereas expression was reversed to control levels in NOSH-A-primed plants or even suppressed in NOSH-primed ones. Previous work demonstrated the negative role of AtGSTU17 in drought tolerance as knock-out plants displayed enhanced tolerance against drought [50], while GST suppression was suggested to take place as a result of plant pre-adaptation to subsequent stress factors, resulting in no further energy consumption needs for the activation of crucial metabolic defense-related pathways [51].

An important biochemical modification induced in plants toward stress protection is the accumulation of osmolytes [52]. Accumulation of the amino acid proline during drought stress improves adaptation by acting as a radical scavenger and osmoprotective agent [53]. The observed increase in proline content in drought-stressed plants is in accordance with previous findings [8], while $\mathrm{NOSH}$ and NOSH-A pre-treatment resulted in increased proline content in drought-stressed plants compared with controls, though to a significantly less pronounced extent compared with unprimed, stressed plants. The present findings suggest that NOSH and NOSH-A priming regulated proline homeostasis, which is crucial for plant growth at a low water potential as it may be used as an energy sink to sustain respiration needs under a water deficit [54] and to maintain high photosynthetic activity [55], ultimately leading to lower proline content in primed, stressed plants compared with unprimed, stressed ones due to a proline reservoir depletion.

Several lines of research suggest that signaling mechanisms in plant systems frequently do not operate as independent pathways, but that extensive cross-talk occurs between signal transduction pathways in a well-orchestrated manner [56]. In support of this observation, NOSHand NOSH-A-priming activity against drought stress through the simultaneous donation of multiple signaling agents provides superior performance compared with individual components, as revealed through a comprehensive pharmacological inhibitor approach. Very few reports exist that have attempted to examine relevant potential synergistic effects, likely due to the complexity of the multifactorial experimental setup required. Even so, contradictory findings have been demonstrated; for example, the combination of NaHS and SNP did not reduce lipid peroxidation further than NaHS and SNP alone in Cd-stressed bermudagrass [57], whereas the combination of SNP with $\mathrm{H}_{2} \mathrm{O}_{2}$ resulted in a concentration-dependent interaction between them regarding heat stress responses in Arabidopsis thaliana [58] and protection against salt stress in basil plants [59]. In a similar fashion, the addition of SA or SNP partially reduced the toxic effects of Ni in canola plants, whereas Ni-stressed plants supplemented with SA + NO exhibited improved growth and photosynthetic pigment content [60]. Interestingly, treatment with $\mathrm{H}_{2} \mathrm{~S}$ inhibitor $\mathrm{HA}$ in $\mathrm{NOSH}$-aspirin pre-treated, drought-stressed plants in the present study resulted in lower cellular damage levels as indicated by an increased MDA content compared with plants treated with $\mathrm{NO}$ inhibitor $\mathrm{CPTIO}$, supporting previous observations that $\mathrm{H}_{2} \mathrm{~S}$ acts downstream of NO in abiotic stress responses [34]. Overall, the important research question on 
whether a combined application of priming agents could act synergistically needs further research in order to be fully elucidated.

\section{Conclusions}

In summary, the current findings demonstrated the capacity of NOSH synthetic compounds to provide significant protection in Medicago sativa plants against drought stress conditions, which resulted in major cellular damage and nitro-oxidative stress in affected plants. This protection appears to be achieved through a coordinated modification of improved physiological performance, reactive oxygen/nitrogen species homeostasis, and transcriptional regulation of defense-related pathways. Therefore, the significant potential for the use of NOSH compounds as priming agents (which has resulted in the Utility Patent Pub. No.: WO/2015/123273) is highlighted in terms of the tolerance enhancement of crop plants when challenged by adverse environmental conditions, with noteworthy beneficial impacts for agricultural production worldwide. Further experiments are being planned in an attempt to translate this technology to crops of agricultural importance, such as cereals, whereby agronomic parameters including yield and biomass will be evaluated, along with comprehensive systems biology approaches that will hopefully contribute to further understanding of NOSH compounds' modus operandi in the regulation of plant priming responses under abiotic stress conditions.

Supplementary Materials: The following are available online at http://www.mdpi.com/2218-273X/10/1/120/s1, Table S1. Oligonucleotide primers used to amplify the targeted genes. Figure S1. Comprehensive set of all treatment phenotypes including inhibitors in (A) 6-day water-stressed and (B) recovered (6-day drought + 1-day rewatering) plants.

Author Contributions: C.A., R.X., G.C. and A.C. carried out the experiments and analyzed the data. K.K. contributed reagents/materials to carry out the experiments and was involved in planning. V.F. conceived, designed and supervised the experiments, and wrote the manuscript. All authors have read and agreed to the published version of the manuscript.

Funding: Current research was supported by the Cyprus University of Technology Internal Grant EX032 to V.F.

Acknowledgments: The authors would like to thank Kyriakos Karmiotis and Evangelia Panagiotou for excellent technical assistance.

Conflicts of Interest: The authors declare no known competing financial interest or personal relationships that could potentially influence the work reported in this paper.

\section{References}

1. Krasensky, J.; Jonak, C. Drought, salt, and temperature stress-induced metabolic rearrangements and regulatory networks. J. Exp. Bot. 2012, 63, 1593-1608. [CrossRef]

2. Beckers, G.J.M.; Conrath, U. Priming for stress resistance: From the lab to the field. Curr. Opin. Plant Biol. 2007, 10, 1-7. [CrossRef]

3. Savvides, A.; Ali, S.; Tester, M.; Fotopoulos, V. Chemical priming against multiple abiotic stresses: Mission possible? Trends Plant Sci. 2016, 21, 329-340. [CrossRef]

4. Islam, M.M.; Hoque, M.A.; Okuma, E.; Banu, M.N.; Shimoishi, Y.; Nakamura, Y.; Murata, Y. Exogenous proline and glycinebetaine increase antioxidant enzyme activities and confer tolerance to cadmium stress in cultured tobacco cells. J. Plant Physiol. 2009, 166, 1587-1597. [CrossRef]

5. Li, T.; Hu, Y.; Du, X.; Tang, H.; Shen, C.; Wu, J. Salicylic acid alleviates the adverse effects of salt stress in Torreya grandis cv. merrillii seedlings by activating photosynthesis and enhancing antioxidant systems. PLoS ONE 2014, 9, e109492.

6. Tanou, G.; Filippou, P.; Belghazi, M.; Job, D.; Diamantidis, G.; Fotopoulos, V.; Molassiotis, A. Oxidative and nitrosative-based signaling and associated post-translational modifications orchestrate the acclimation of citrus plants to salinity stress. Plant J. 2012, 72, 585-599. [CrossRef] [PubMed]

7. Christou, A.; Filippou, P.; Manganaris, G.A.; Fotopoulos, V. Sodium hydrosulfide induces systemic thermotolerance to strawberry plants through transcriptional regulation of heat shock proteins and aquaporin. BMC Plant Biol. 2014, 14, 42. [CrossRef] 
8. Antoniou, C.; Chatzimichail, G.; Xenofontos, R.; Pavlou, J.J.; Panagiotou, E.; Christou, A.; Fotopoulos, V. Melatonin systemically ameliorates drought stress-induced damage in Medicago sativa plants by modulating nitro-oxidative homeostasis and proline metabolism. J. Pineal Res. 2017, 62, e12401. [CrossRef] [PubMed]

9. Casenave, E.C.; Toselli, M.E. Hydropriming as a pretreatment for cotton germination under thermal and water stress conditions. Seed Sci. Technol. 2007, 35, 88-98. [CrossRef]

10. Molassiotis, A.; Fotopoulos, V. Oxidative and nitrosative signaling in plants. Plant Signal. Behav. 2011, 6, 210-214. [CrossRef]

11. Fotopoulos, V.; Christou, A.; Antoniou, C.; Manganaris, G.A. Hydrogen sulphide: A versatile tool for the regulation of growth and defence responses in horticultural crops. J. Hortic. Sci. Biotechnol. 2015, 90, 227-234. [CrossRef]

12. Calderwood, A.; Kopriva, S. Hydrogen sulfide in plants: From dissipation of excess sulfur to signaling molecule. Nitric Oxide 2014, 41, 72-78. [CrossRef] [PubMed]

13. Kodela, R.; Chattopadhyay, M.; Kashfi, K. NOSH-aspirin: A novel nitric oxide-hydrogen sulfide-releasing hybrid: A new class of anti-inflammatory pharmaceuticals. ACS Med. Chem. Lett. 2012, 3, 257-262. [CrossRef] [PubMed]

14. Chattopadhyay, M.; Kodela, R.; Olson, K.R.; Kashfi, K. NOSH-aspirin (NBS-1120), a novel nitric oxide- and hydrogen sulfide-releasing hybrid is a potent inhibitor of colon cancer cell growth in vitro and in a xenograft mouse model. Biochem. Biophys. Res. Commun. 2012, 419, 523-528. [CrossRef] [PubMed]

15. Vannini, F.; Chattopadhyay, M.; Kodela, R.; Rao, P.P.N.; Kashfi, K. Positional isomerism markedly affects the growth inhibition of colon cancer cells by NOSH-aspirin: COX inhibition and modeling. Redox Biol. 2015, 6, 318-325. [CrossRef] [PubMed]

16. Lee, M.; McGeer, E.; Kodela, R.; Kashfi, K.; McGeer, P.L. NOSH-aspirin (NBS-1120), a novel nitric oxide and hydrogen sulfide releasing hybrid, attenuates neuroinflammation induced by microglial and astrocytic activation: A new candidate for treatment of neurodegenerative disorders. Glia 2013, 61, 1724-1734. [CrossRef]

17. Antoniou, C.; Savvides, A.; Christou, A.; Fotopoulos, V. Unravelling chemical priming machinery in plants: The role of reactive oxygen-nitrogen-sulfur species in abiotic stress tolerance enhancement. Curr. Opin. Plant Biol. 2016, 33, 101-107. [CrossRef]

18. Rajjou, L.; Belghazi, M.; Huguet, R.; Robin, C.; Moreau, A.; Job, C.; Job, D. Proteomic investigation of the effect of salicylic acid on Arabidopsis seed germination and establishment of early defense mechanisms. Plant Physiol. 2006, 141, 910-923. [CrossRef]

19. Christou, A.; Manganaris, G.A.; Papadopoulos, I.; Fotopoulos, V. Hydrogen sulfide induces systemic tolerance to salinity and non-ionic osmotic stress in strawberry plants through modification of reactive species biosynthesis and transcriptional regulation of multiple defense pathways. J. Exp. Bot. 2013, 64, 1953-1966. [CrossRef]

20. Loreto, F.; Velikova, V. Isoprene produced by leaves protects the photosynthetic apparatus against ozone damage, quenches ozone products, and reduces lipid peroxidation of cellular membranes. Plant Physiol. 2001, 127, 1781-1787. [CrossRef]

21. Zhou, B.; Guo, Z.; Xing, J.; Huang, B. Nitric oxide is involved in abscisic acid-induced antioxidant activities in Stylosanthes guianensis. J. Exp. Bot. 2005, 56, 3223-3228. [CrossRef] [PubMed]

22. Nashef, A.S.; Osuga, D.T.; Feeney, R.E. Determination of hydrogen sulfide with 5,5 $\beta^{\prime}$-dithiobis-(2-nitrobenzoic acid), N-ethylmaleimide, and parachloromercuribenzoate. Anal. Biochem. 1977, 79, 394-405. [CrossRef]

23. Bates, L.S.; Waldren, R.P.; Teare, I.D. Rapid determination of free proline for water-stress studies. Plant Soil 1973, 39, 205-207. [CrossRef]

24. Bradford, M.M. A rapid and sensitive method for the quantitation of microgram quantities of protein utilizing the principle of protein dye binding. Anal. Biochem. 1976, 72, 248-254. [CrossRef]

25. Giannopolitis, C.N.; Ries, S.K. Superoxide dismutase. I. Occurrence in higher plants. Plant Physiol. 1977, 59, 309-314. [CrossRef] [PubMed]

26. Aebi, H. Catalase in vitro. Methods Enzymol. 1984, 105, 121-126. [PubMed]

27. Filippou, P.; Bouchagier, P.; Skotti, E.; Fotopoulos, V. Proline and reactive oxygen/nitrogen species metabolism is involved in the tolerant response of the invasive plant species Ailanthus altissima to drought and salinity. Environ. Exper. Bot. 2014, 97, 1-10. [CrossRef] 
28. Pfaffl, M.W.; Horgan, G.W.; Dempfle, L. Relative expression software tool (RESTB@) for group-wise comparison and statistical analysis of relative expression results in real-time PCR. Nucleic Acids Res. 2002, 30, e36. [CrossRef]

29. Filippou, P.; Antoniou, C.; Obata, T.; Van Der Kelen, K.; Harokopos, V.; Kanetis, L.; Aidinis, V.; Van Breusegem, F.; Fernie, A.R.; Fotopoulos, V. Kresoxim-methyl primes Medicago truncatula plants against abiotic stress factors via altered reactive oxygen and nitrogen species signalling leading to downstream transcriptional and metabolic readjustment. J. Exp. Bot. 2016, 67, 1259-1274. [CrossRef]

30. Zhu, J.K. Salt and drought stress signal transduction in plants. Annu. Rev. Plant Biol. 2002, 53, $247-273$. [CrossRef]

31. Uchida, A.; Jagendorf, A.T.; Hibino, T.; Takabe, T.; Takabe, T. Effects of hydrogen peroxide and nitric oxide on both salt and heat stress tolerance in rice. Plant Sci. 2002, 163, 515-523. [CrossRef]

32. Zhang, J.Y.; Cruz De Carvalho, M.H.; Torres-Jerez, I.; Kang, Y.; Allen, S.N.; Huhman, D.V.; Tang, Y.; Murray, J.; Sumner, L.W.; Udvardi, M.K. Global reprogramming of transcription and metabolism in Medicago truncatula during progressive drought and after rewatering. Plant Cell Environ. 2014, 37, 2553-2576. [CrossRef] [PubMed]

33. Vinocur, B.; Altman, A. Recent advances in engineering plant tolerance to abiotic stress: Achievements and limitations. Curr. Opin. Biotechnol. 2005, 16, 123-132. [CrossRef] [PubMed]

34. Corpas, F.J.; González-Gordo, S.; Cañas, A.; Palma, J.M. Nitric oxide and hydrogen sulfide in plants: Which comes first? J. Exp. Bot. 2019, 70, 4391-4404. [CrossRef] [PubMed]

35. Khan, M.I.R.; Fatma, M.; Per, T.S.; Anjum, N.A.; Khan, N.A. Salicylic acid-induced abiotic stress tolerance and underlying mechanisms in plants. Front. Plant Sci. 2015, 6, 462. [CrossRef] [PubMed]

36. Gill, S.S.; Tuteja, N. Reactive oxygen species and antioxidant machinery in abiotic stress tolerance in crop plants. Plant Physiol. Biochem. 2010, 48, 909-930. [CrossRef]

37. Christou, A.; Manganaris, G.A.; Fotopoulos, V. Systemic mitigation of salt stress by hydrogen peroxide and sodium nitroprusside via transcriptional regulation of enzymatic and non-enzymatic antioxidants. Environ. Exper. Bot. 2014, 107, 46-54. [CrossRef]

38. Alavi, S.M.N.; Arvin, M.J.; Kalantari, K.M. Salicylic acid and nitric oxide alleviate osmotic stress in wheat (Triticum aestivum L.) seedlings. J. Plant Inter. 2014, 9, 683-688.

39. Habibi, G. Exogenous salicylic acid alleviates oxidative damage of barley plants under drought stress. Acta Biol. Szeged. 2012, 56, 57-63.

40. Chen, J.; Wu, F.H.; Wang, W.H.; Zheng, C.J.; Lin, G.H.; Dong, X.J.; He, J.X.; Pei, Z.M.; Zheng, H.L. Hydrogen sulphide enhances photosynthesis through promoting chloroplast biogenesis, photosynthetic enzyme expression, and thiol redox modification in Spinacia oleracea seedlings. J. Exp. Bot. 2011, 62, 4481-4493. [CrossRef]

41. Ziogas, V.; Tanou, G.; Belghazi, M.; Filippou, P.; Fotopoulos, V.; Diamantidis, G.; Molassiotis, A. Roles of sodium hydrosulfide and sodium nitroprusside as priming molecules during drought acclimation in citrus plants. Plant Mol. Biol. 2015, 89, 433-450. [CrossRef] [PubMed]

42. Jubany-Mari, T.; Munné-Bosch, S.; Alegre, L. Redox regulation of water stress responses in field-grown plants. Role of hydrogen peroxide and ascorbate. Plant Physiol. Biochem. 2010, 48, 351-358. [CrossRef] [PubMed]

43. Valderrama, R.; Corpas, F.J.; Carreras, A.; Fernández-Ocaña, A.; Chaki, M.; Luque, F.; Gómez-Rodríguez, M.V.; Colmenero-Varea, P.; del Río, L.A.; Barroso, J.B. Nitrosative stress in plants. FEBS Lett. 2007, 581, $453-461$. [CrossRef] [PubMed]

44. Zhang, H.; Jiao, H.; Jiang, C.X.; Wang, S.H.; Wei, Z.J.; Luo, J.P.; Jones, R. Hydrogen sulfide protects soybean seedlings against drought-induced oxidative stress. Acta Physiol. Plantar. 2010, 32, 849-857. [CrossRef]

45. Lisjak, M.; Srivastava, N.; Teklic, T.; Civale, L.; Lewandowski, K.; Wilson, I.; Wood, M.E.; Whiteman, M.E.; Hancock, J.T. A novel hydrogen sulfide donor causes stomatal opening and reduces nitric oxide accumulation. Plant Physiol. Biochem. 2010, 48, 931-935. [CrossRef] [PubMed]

46. Borsani, O.; Diaz, P.; Agius, M.F.; Valpuesta, V.; Monza, J. Water stress generates an oxidative stress through the induction of a specific $\mathrm{Cu} / \mathrm{Zn}$ superoxide dismutase in Lotus corniculatus leaves. Plant Sci. 2001, 161, 757-763. [CrossRef]

47. Fotopoulos, V.; Antoniou, C.; Filippou, P.; Mylona, P.; Fasoula, D.; Ioannides, I.; Polidoros, A. Application of sodium nitroprusside results in distinct antioxidant gene expression patterns in leaves of mature and senescing. Medicago truncatula plants. Protoplasma 2014, 251, 973-978. [CrossRef] [PubMed] 
48. Ara, N.; Nakkanong, K.; Lv, W.; Yang, J.; Hu, Z.; Zhang, M. Antioxidant enzymatic activities and gene expression associated with heat tolerance in the stems and roots of two Cucurbit species ("Cucurbita maxima" and "Cucurbita moschata") and their interspecific inbred line "Maxchata". Int. J. Mol. Sci. 2013, 14, 24008-24028. [CrossRef] [PubMed]

49. George, S.; Venkataraman, G.; Parida, A. A chloroplast-localized and auxin-induced glutathione $S$-transferase from phreatophyte Prosopis juliflora confer drought tolerance on tobacco. J. Plant Physiol. 2010, 167, 311-318. [CrossRef]

50. Chen, J.H.; Jiang, H.W.; Hsieh, E.J.; Chen, H.Y.; Chien, C.T.; Hsieh, H.L.; Lin, T.P. Drought and salt stress tolerance of an Arabidopsis glutathione S-transferase U17 knockout mutant are attributed to the combined effect of glutathione and abscisic acid. Plant Physiol. 2012, 158, 340-351. [CrossRef]

51. Sanchez, D.H.; Pieckenstain, F.L.; Escaray, F.; Erban, A.; Kraemer, U.; Udvardi, M.K.; Kopka, J. Comparative ionomics and metabolomics in extremophile and glycophytic Lotus species under salt stress challenge the metabolic pre-adaptation hypothesis. Plant Cell Environ. 2011, 34, 605-617. [CrossRef] [PubMed]

52. Ashraf, M.; Foolad, M.R. Roles of glycine betaine and proline in improving plant abiotic stress resistance. Environ. Exp. Bot. 2007, 59, 206-216. [CrossRef]

53. Matysik, J.A.; Bhalu, B.; Mohanty, P. Molecular mechanisms of quenching of reactive oxygen species by proline under stress in plants. Curr. Sci. 2002, 82, 525-532.

54. Sharma, S.; Villamor, J.G.; Verslues, P.E. Essential role of tissue-specific proline synthesis and catabolism in growth and redox balance at low water potential. Plant Physiol. 2011, 157, 292-304. [CrossRef]

55. Akbari, G.A.; Hojati, M.; Modarres-Sanavy, S.A.M.; Ghanati, F. Exogenously applied hexaconazole ameliorates salinity stress by inducing an antioxidant defense system in Brassica napus L. plants. Pestic. Biochem. Physiol. 2011, 100, 244-250. [CrossRef]

56. Knight, H.; Knight, M.R. Abiotic stress signalling pathways: Specificity and cross-talk. Trends Plant Sci. 2001, 6, 262-267. [CrossRef]

57. Shi, H.; Ye, T.; Chan, Z. Nitric oxide-activated hydrogen sulfide is essential for cadmium stress response in bermudagrass (Cynodon dactylon (L). Pers.). Plant Physiol. Biochem. 2014, 74, 99-107. [CrossRef]

58. Wu, D.; Chu, H.; Jia, L.; Chen, K.; Zha, L. A feedback inhibition between nitric oxide and hydrogen peroxide in the heat shock pathway in Arabidopsis seedlings. Plant Growth Regul. 2015, 75, 503-509. [CrossRef]

59. Gohari, G.; Alvai, Z.; Esfandiari, E.; Panahirad, S.; Hajihoseinlou, S.; Fotopoulos, V. Interaction between hydrogen peroxide $\left(\mathrm{H}_{2} \mathrm{O}_{2}\right)$ and sodium nitroprusside (SNP) following chemical priming of Ocimum basilicum L. against salt stress. Physiol. Plantar. 2019. [CrossRef]

60. Kazemi, N.; Khavari-Nejad, R.A.; Fahimi, H.; Saadatmand, S.; Nejad-Sattari, T. Effects of exogenous salicylic acid and nitric oxide on lipid peroxidation and antioxidant enzyme activities in leaves of Brassica napus L. under nickel stress. Sci. Hortic. 2010, 126, 402-407. [CrossRef]

(C) 2020 by the authors. Licensee MDPI, Basel, Switzerland. This article is an open access article distributed under the terms and conditions of the Creative Commons Attribution (CC BY) license (http://creativecommons.org/licenses/by/4.0/). 